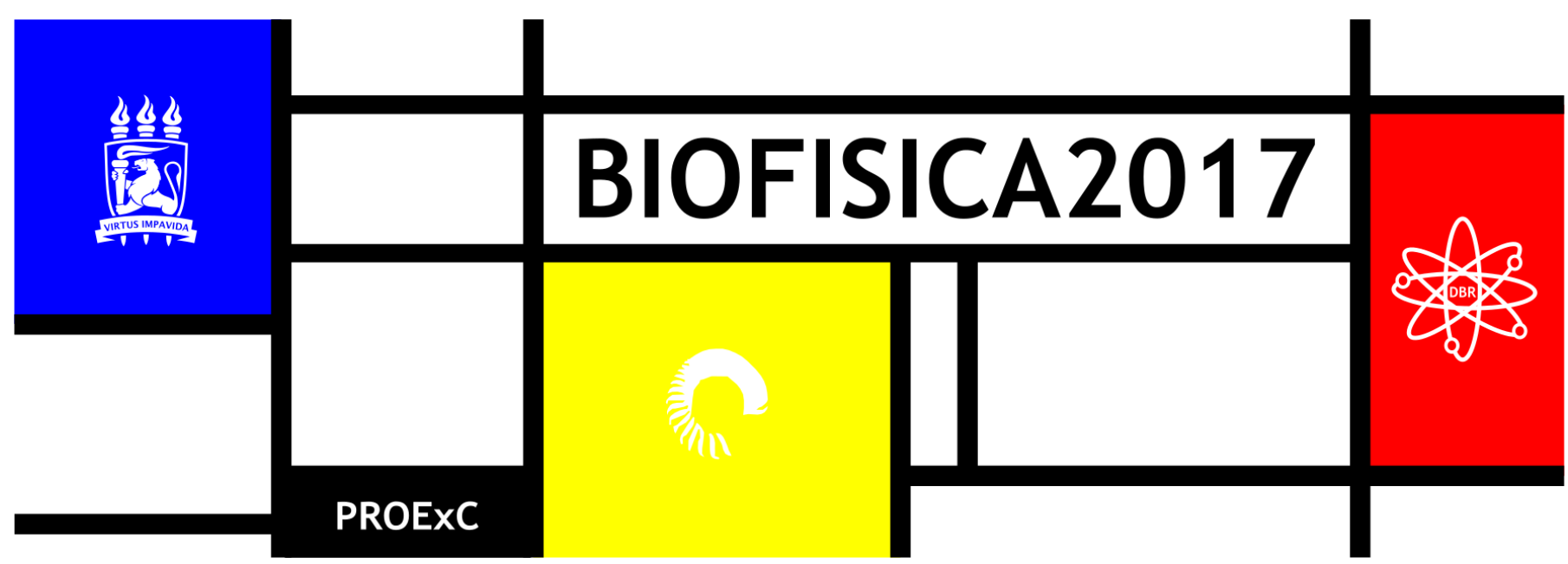

\title{
ATIVIDADE ANTIOXIDANTE E QUANTIFICAÇÃO DE COMPOSTOS FENÓLICOS BIOATIVOS DA ESPÉCIE DO SEMIÁRIDO BAUHINIA CHEILANTHA (BONG.) STEUD.
}

\author{
Maria Giuliane G. da Silva ${ }^{1 *}$, Edson Renan B. de Santana ${ }^{1}$, Rafael J. A. dos Santos Padilha ${ }^{1}$, Cláudia Sampaio de \\ Andrade Lima ${ }^{1}$, Ricardo Yara ${ }^{2}$
}

${ }^{1}$ Laboratório de Biofísica, UFPE; ${ }^{2}$ Laboratório de Engenharia Biomédica, UFPE *erbs2k@gmail.com

\section{INTRODUÇÃO}

A Caatinga, principal ecossistema do semiárido brasileiro, é considerada uma região rica em recursos naturais, porém ainda pouco explorada. Nessa região é encontrada uma variedade enorme de espécies ricas em princípios ativos com as mais diversas atividades biológicas. Várias espécies medicinais da caatinga e dos brejos de altitude são amplamente utilizadas na medicina popular e na formulação de produtos fitoterápicos. No entanto, os estudos químicos e biológicos na região ainda são escassos, diante da grande diversidade apresentada. A Bauhinia cheilantha (Bong.) Steud., conhecida popularmente como pata-de-vaca ou mororó, é uma planta leguminosa típica da Caatinga. A espécie é usada na produção de remédios caseiros com ação antiinflamatória, antidiabética, sedativa, antiparasitária, para distúrbios digestivos, asma e tosse e para uso alimentar como bebida, a partir de suas sementes torradas (ALBUQUERQUE et al., 2007; AGRA et al., 2007). $\mathrm{Na}$ espécie $B$. cheilantha já foi relatada a presença de diferentes classes de compostos orgânicos de interesse medicinal, como os alcalóides, as antraquinonas, esteróides livres, flavonas, flavonóides e xantonas (folhas, madeira e raízes), fenóis (caule, folha), flavononas (caule, raiz) (LUNA et al., 2005). Compostos fenólicos como as citadas flavonas e os flavonoides, por exemplo, estão associados a atividade antioxidante, que é uma ação que retarda ou impede o dano oxidativo, processo causado por substâncias chamadas radicais livres, que podem levar à disfunção das células e o aparecimento de problemas como doenças cardíacas, diabetes e câncer. Mediante o exposto, o presente estudo teve por objetivo avaliar a atividade antioxidante e verificar, através de técnicas quantitativas, a presença de fenóis totais e flavonoides em extratos de $B$. cheilantha.

\section{MATERIAIS E MÉTODOS}

A coleta da $B$. cheilantha foi realizada no município de Brejo da Madre de Deus-PE. O material vegetal foi colocado em estufa com circulação de ar forçada a $45^{\circ}$. Após secagem, as folhas foram separadas, trituradas e colocadas em um percolador de aço inoxidável, no qual foi acrescentado etanol para a obtenção do extrato bruto. Após a extração o material foi levado ao evaporador rotativo para retirada total do solvente. $\mathrm{A}$ atividade antioxidante foi determinada através do teste da redução do radical DPPH $(2,2-$ difenil-1-picril-hidrazila) seguindo a metodologia proposta por Nascimento e colaboradores (2011). A partir do extrato etanólico foram preparadas soluções das amostras nas concentrações de 1000,500 e $250 \mu \mathrm{g} / \mathrm{mL}$. Um controle negativo foi feito pela adição de etanol e DPPH e o controle positivo foi feito pela adição de solução de um padrão (rutina) e DPPH. Adicionou-se a cada concentração de extrato etanólico uma solução de DPPH $300 \mu \mathrm{M}$, exceto nos brancos, onde foi adicionado o solvente. Após a adição do DPPH, esperou-se 40 minutos e procedeu-se a leitura no espectrofotômetro a $515 \mathrm{~nm}$. A análise quantitativa de compostos fenólicos (totais) nos extratos foi realizada utilizando-se o método espectrofotométrico (SINGLETON et al., 1999). A solução metanólica do extrato na concentração de $1 \mathrm{mg} / \mathrm{mL}$ foi utilizada na análise. A mistura de reação foi preparada misturando-se uma alíquota da solução metanólica do extrato com o reagente de Folin-Ciocalteu (10\%) e $\mathrm{NaHCO}_{3}$ a $7,5 \%$. As amostras foram preparadas em triplicata $(1000,500,250 \mu \mathrm{g} / \mathrm{mL})$ e o valor médio de absorbância foi obtido. 0 mesmo procedimento foi repetido para a solução padrão que consistiu em ácido gálico, a partir da qual foi criada uma curva de calibração. As amostras foram incubadas num banho termostatizado e posteriormente procedeuse a leitura em um espectrofotômetro de UV-Vis no comprimento de onda em $765 \mathrm{~nm}(\lambda)$. O conteúdo de compostos fenólicos presentes em extratos foi expresso em termos de equivalentes de ácido gálico (mg de GA/g de extrato) (STANKOVIC, 2012). Para a determinação de flavonóides seguiu-se a metodologia proposta por Woisky e Salatino (1998) adaptada. O experimento consiste adicionar ao extrato o reagente cloreto de alumínio $\left(\mathrm{AlCl}_{3}, 5 \%\right)$ (hexahidratado), dissolvido em metanol. 0 branco foi preparado utilizando-se apenas o metanol e o cloreto de alumínio. A leitura e procedeu-se em espectrofotômetro com comprimento de onda a $425 \mathrm{~nm}$. Foi utilizada como padrão a quercetina, nas concentrações de $1000,500,250 \mu \mathrm{g} / \mathrm{mL}$ para a construção da curva de calibração. A partir da equação da reta obtida, realiza-se o cálculo do teor de flavonóides, expresso em equivalente quercetina de amostra $(\mathrm{mg}$ de QUE/g de extrato). 


\section{RESULTADOS E DISCUSSÃO}

Os resultados do teste de DPPH para os extratos de $B$. cheilantha indicaram um alto percentual de atividade antioxidante. Os valores estão expostos na tabela 1 .

Tabela 1. Resultado teste de atividade antioxidante pela redução do radical DPPH para os extratos de $B$. cheilantha.

\begin{tabular}{lc}
\hline Concentração & $\begin{array}{c}\text { \% de atividade } \\
\text { antioxidante }\end{array}$ \\
\hline $1000 \mu \mathrm{g} / \mathrm{ml}$ & 85 \\
$500 \mu \mathrm{g} / \mathrm{ml}$ & 87 \\
$250 \mu \mathrm{g} / \mathrm{ml}$ & 74 \\
\hline
\end{tabular}

A relação dos compostos fenólicos com a atividade antioxidante já é amplamente encontrada na literatura (DEGÁSPARI \& WASZCZYNSKYJ, 2004; ACHKAR et al., 2014). Os resultados dos testes quantitativos para verificação de fenóis totais (Tabela 2) e para a presença de flavonoides (Tabela 3) embasam os valores encontrados no teste do DPPH.

Tabela 2. Resultado da análise quantitativa para fenóis totais presentes nos extratos de B. cheilantha

\begin{tabular}{lcc}
\hline Concentração & $\begin{array}{c}\text { mg de Ac. Gal./g } \\
\text { de extrato }\end{array}$ & Desvio Padrão \\
\hline $1000 \mu \mathrm{g} / \mathrm{ml}$ & 103.244 & 4,9 \\
$500 \mu \mathrm{g} / \mathrm{ml}$ & 62,729 & 0,9 \\
$250 \mu \mathrm{g} / \mathrm{ml}$ & 38,463 & 3,9 \\
\hline
\end{tabular}

Tabela 3. Resultado da análise quantitativa para flavonóides presentes nos extratos de $B$. cheilantha.

\begin{tabular}{lcc}
\hline Concentração & mg de Que/g de extrato & Desvio Padrão \\
\hline $1000 \mu \mathrm{g} / \mathrm{ml}$ & 119.541 & 4,75 \\
$500 \mu \mathrm{gl} / \mathrm{ml}$ & 72,605 & 3,1 \\
$250 \mu \mathrm{g} / \mathrm{ml}$ & 37,423 & 3,0 \\
\hline
\end{tabular}

O gênero Bauhinia possui várias espécies que destacam-se por possuírem atividade antioxidante, o que corrobora com os dados obtidos por nós onde mais uma espécie desse gênero se inclui ao rol de plantas com tal atividade (BRACA et al., 2001; SOUSA et al., 2004; ARGOLO et al., 2004; NASCIMENTO et al., 2011)

\section{CONCLUSÕES}

A espécie Bauhinia cheilantha apresentou potencial antioxidante elevado, o que foi validado através da avaliação quantitativa de compostos fenólicos presentes na mesma. Produtos naturais que possuem atividade antioxidante são sempre alvo de interesse de estudos, principalmente visando a produção de fitoterápicos. A descoberta de espécies pertencentes ao semiárido nordestino ressalta a importância da preservação e ao mesmo tempo da exploração racional desse ecossistema.

\section{REFERÊNCIAS}

ACHKAR, M. T.; NOVAES, G. M.; SILVA, M. J. D.; VILEGAS, W. Propriedade antioxidante de compostos fenólicos: importância na dieta e na conservação de alimentos. Revista da Universidade Vale do Rio Verde, v. 11, n. 2, p. 398-406, 2013.

AGRA, Maria de Fátima et al. Medicinal and poisonous diversity of the flora of "Cariri Paraibano", Brazil. Journal of Ethnopharmacology, v. 111, p. 383-395, 2007.

ALBUQUERQUE, Ulisses Paulino et al. Medicinal plants of the caatinga (semi-arid) vegetation of NE Brazil: A quantitative approach. Journal of Ethnopharmacology, v. 114, p. 325-354, 2007. ARGOlO, A. C. C.; SANT'ANA, A. E. G.; PLETSCH, M.; COELHO, L. C. B. B. Antioxidant activity of leaf extracts from Bauhinia monandra. Bioresour. Technol., 95, 229-233, 2004.

BRACA, A.; TOMMASI, N.; BARI, L.; PIZZA, C.; POLITI, M.; MORELLI, I. Antioxidant Principles from Bauhinia tarapotensis. J. Nat. Prod., v. 64 (7), p. 892-895, 2001.

DEGÁSPARI, C. H.; WASZCZYNSKYJ, N. Propriedades antioxidantes de compostos fenólicos. Visão Acadêmica, Curitiba, v. 5 (1), p. 3340, 2004.
LUNA, J. DE S. et al. A study of the larvicidal and molluscicidal activities of some medicinal plants from northeast Brazil. Journal of Ethnopharmacology, v. 97, n. 2, p. 199-206, fev. 2005.

NASCIMENTO, J. C.; LAGE, L. F. O.; CAMARGOS, C. R. D.; AMARAL, J. C.; COSTA, L. M.; SOUSA, N. A.; OLIVEIRA, F. Q. Determinação da atividade antioxidante pelo método DPPH e doseamento de flavonóides totais em extratos de folhas da Bauhinia variegata $\mathrm{L}$. Rev. Bras. Farm. 2011; 92 (4): 327-332.

SINGLETON, V. L.; ORTHOFER, R.; LAMUELA-RAVENTÓS, R. M. Analysis of total phenols and other oxidation substrates and antioxidants by means of folin-ciocalteu reagent. Methods in Enzymology. V. 299, p. 152-178, 1999.

SOUSA, E. et al. Hypoglycemic effect and antioxidant potential of kaempferol-3,7-0-(a)-dirhammnoside from Bauhinia forficata leaves. Journal of Natural Products, v. 67, p. 829-832, 2004.

WOISKY, R. G; SALATINO, A. Analysis os propolis: some parameters ond prodecore for chemical fuality control. Journal Apicultural Research, 1998. 